\title{
Study of lipid profile in adult women with acne
}

This article was published in the following Dove Press journal:

Clinical, Cosmetic and Investigational Dermatology

17 August 2015

Number of times this article has been viewed

Marisa Gonzaga da Cunha'

Anna Luiza Fonseca Batista'

Marzia Silva Macedo'

Carlos D'Aparecida Santos

Machado Filho'

Fernando Luiz Affonso

Fonseca $^{2}$

'Dermatology Department, Faculdade de Medicina do $A B C$ (FMABC), Santo André, São Paulo, Brazil; ${ }^{2}$ Biological Sciences Department, Universidade Federal de São Paulo (UNIFESP),

Diadema, São Paulo, Brazil
Correspondence: Fernando Luiz Affonso Fonseca

Faculdade de Medicina do ABC Av Principe de Gales, n82I, Santo André 09060-650, São Paulo, Brazil Email profferfonseca@gmail.com
Objective: The aim of this study was to establish the lipid profile of female patients with acne in the Acne-in-Adult-Women Ambulatory Care Clinic in order to observe the prevalence of dyslipidemia in those patients.

Methods: This is a retrospective transversal study that evaluated the medical records of 416 patients who attended at the Acne-in-Adult-Women Ambulatory Care Clinic, at the Dermatology Department, Faculdade de Medicina do ABC, Santo André, São Paulo, Brazil, in the year 2012. Relevant data included age and clinical classification of acne. The lipid profile was analyzed according to the results of laboratory tests ordered during outpatient visits, which included total and fractionated cholesterol levels and triglycerides.

Results: The epidemiological study sample was of 219 patients, with ages ranging from 21 to 61 years (mean of 32.23 years). The predominant clinical grade was papule-pustule acne (grade II) with 156 patients (71\%). Regarding the lipid profile of the patients, there was a high increase in total cholesterol levels in $17.35 \%$ of the cases. High-density lipoprotein levels were low in $11.42 \%$ of the patients, with normal prevalence in 194 subjects. Low-density lipoprotein levels were normal in most patients $(60.27 \%)$. Very-low-density lipoprotein values were normal in almost all patients $(94.06 \%)$ and increased in only 13 patients $(5.94 \%)$. Only 18 patients presented high levels of triglycerides (8.22\%).

Conclusion: The conclusion was that patients with grades II and III acne are more likely to have total cholesterol and low-density lipoprotein altered. A correct and early diagnosis can be an important measure for the prevention of the metabolic syndrome in these patients.

Keywords: acne, hyperandrogenism, dyslipidemia, cholesterol, triglycerides

\section{Introduction}

Acne is one of the major concerns during dermatology consultations owing to its high incidence and influence on patient sociability and self-esteem. ${ }^{1}$ Its physiopathology includes increase in sebum production, follicular hyperkeratinization, Propionibacterium acnes colonization, and release of inflammatory mediators in adjacent follicles and dermis..$^{2-4}$ These phenomena are related to the increase in the production of androgens, synthesized by the ovaries and the adrenal glands from cholesterol in females, along with their conversion in peripheral tissues. ${ }^{5}$ Levels of circulating androgens may be normal; however, local conversion may be increased due to a higher sensitivity of the receptors. ${ }^{4,6}$

Androgens can stimulate sebum production through many mechanisms: through androgen antagonism in the sebaceous glands, through inhibition of female gonadal hormone production by means of negative feedback, or through direct stimulation of lipid production. ${ }^{7}$ 
Although acne incidence peaks during adolescence, $40 \%-55 \%$ of the population over 25 years of age presents episodes of acne. "Acne in adult women" is defined as a persistent or new onset of acne lesions after the age of $21 .{ }^{9}$ Some authors consider 15 years as the age limit, since an improvement in acne scarring is expected 2 years after the first menarche. ${ }^{10}$ In this group, hyperandrogenism plays a fundamental role, affecting 5\%-10\% of childbearing-age females all over the world. ${ }^{11}$

Clinically speaking, hyperandrogenism manifests in females as hirsutism, acne, seborrhea, alopecia, menstrual irregularities, and ovulatory dysfunction. ${ }^{12}$ Polycystic ovary syndrome (PCOS) is its main cause and represents two-thirds of the diagnosis. ${ }^{9,12}$

Among women, this is the most common endocrine disorder with a prevalence of $6 \%-10 \%$, based on the National Institute of Health criteria, and of $15 \%$, according to the Rotterdam criteria. Both consensus standards are used for the diagnosis of PCOS..$^{13}$

In addition to the acne condition, PCOS is also associated with plurimetabolic syndrome manifestations, like hyperinsulinemia, glucose intolerance, dyslipidemia, and visceral obesity.9,14,15 Recent evidences show a low-grade chronic inflammatory activity in PCOS. It may be considered as one of the potential relations between the syndrome and metabolic and cardiovascular complications in the long run due to the vicious circle that is established with the continuous release of inflammatory mediators, which are responsible for the development of peripheral resistance to insulin, dyslipidemia, and endothelial dysfunction. ${ }^{16}$

The PCOS etiopathogeny is not fully known yet. However, its association with abnormal steroidogenesis and insulin resistance has been described in the literature. ${ }^{6,17}$ Insulin resistance is present in $50 \%-70 \%$ of the women with PCOS, regardless of the coexisting obesity, and it is a triggering factor for hyperandrogenism owing to hepatic alterations and the direct stimulation of ovarian androgen hypersecretion as a consequence of the compensatory hyperinsulinemia. ${ }^{4,13,15,16,18,19}$

Dyslipidemia is the most common metabolic abnormality in women with PCOS, since $70 \%$ of these patients have alterations in lipid profiles similar to those mentioned in insulin-resistant patients. ${ }^{13,20-24}$ Among lipid alterations, highdensity lipoprotein (HDL) seems to be the best risk indicator for cardiovascular diseases in the PCOS. ${ }^{13,24}$ The most known effect of androgens on lipid metabolism is related to HDL catabolism; in other words, androgens can increase hepatic lipase activity, which coincides with the increase observed during its activity in the PCOS. ${ }^{21,24}$
The increase in levels of plasma cholesterol leads to the androgen production increase, which, in turn, is one of the major predisposing factors for the onset of acne lesions. ${ }^{25}$

Studies on the relation between dyslipidemia and the onset of acne have divergent results, and therefore they are not clearly related in the literature. Some of them reveal that the lipid profile in adult women with acne shows an increase of total cholesterol (TC) and low-density lipoprotein (LDL) and a decrease in HDL, ${ }^{25}$ namely the same profile described in the PCOS. Another study indicates that levels of TC as well as of triglycerides (TG) in patients with acne, when compared with control group, were not significantly different. Alterations were restricted to HDL levels, which significantly decrease in patients with lesions, and to LDL levels, which increase as the acne condition becomes more severe. $^{26}$

In view of the lack of studies and consensus on the relationship between dyslipidemia and acne in the literature, this study aims to establish the lipid profile of female patients with acne in the Acne-in-Adult-Women Ambulatory Care Clinic of ABC Medical School (FMABC), Santo André, São Paulo, Brazil, in order to observe the prevalence of dyslipidemia in those patients.

\section{Methods}

This is a retrospective transversal study that evaluates the medical records of 416 patients who attended at FMABC Dermatology Department, in the Acne-in-Adult-Women Ambulatory Care Clinic in Santo André, São Paulo, Brazil, over a period of 1 year. Dr Marisa Gonzaga da Cunha, who is in charge of the ambulatory, supervised the project.

\section{Studied population}

The study included records of patients who attended the ambulatory care unit between the period of January and December of 2012.

- Inclusion criteria: female patients aged $\geq 21$ years with papule-pustule or nodule-cystic acne cases.

- Exclusion criteria: patients aged $<21$ years, patients whose laboratory evaluations were incomplete, patients with comedogenic acne given the fact this is an event that can be triggered by occlusive external agents like the inadequate topic use of comedogenic products.

\section{Analyzed parameters}

The data that were taken into consideration included age and the following clinical classification of acne: comedogenic acne, with prevalence of comedones - grade I; papule-pustule 
acne, with inflammatory lesions topped with pustules or not - grade II; nodule-cystic acne, with prevalence of inflammatory nodules - grade III. ${ }^{27}$

The lipid profile was analyzed according to the results obtained from the laboratory exams requested during patients' first visit. Exams included levels of TC and fractions (HDL, very-low-density lipoprotein [VLDL], LDL) and TG. Reference ranges, according to the Clinical Analysis Laboratory at the FMABC, were:

- $\quad$ TC ( $>19$ years $)-$ desirable $<200 \mathrm{mg} / \mathrm{dL}$; borderline high 200-239 mg/dL; high $\geq 240 \mathrm{mg} / \mathrm{dL}$.

- $\operatorname{HDL}(>19$ years $)-\geq 40 \mathrm{mg} / \mathrm{dL}$.

- LDL ( $>20$ years) - optimal $<100 \mathrm{mg} / \mathrm{dL}$; near optimal 100-129 mg/dL; borderline high 130-159 mg/dL; high $160-189 \mathrm{mg} / \mathrm{dL}$; very high $>189 \mathrm{mg} / \mathrm{dL}$.

- VLDL $-\leq 50 \mathrm{mg} / \mathrm{dL}$.

- $\mathrm{TG}$ ( $>19$ years) - optimal $<150 \mathrm{mg} / \mathrm{dL}$; borderline high $150-200 \mathrm{mg} / \mathrm{dL}$; high $201-499 \mathrm{mg} / \mathrm{dL}$; very high $\geq 500 \mathrm{mg} / \mathrm{dL}$.

TC, HDL, and TG were determined using an enzymatic colorimetric test, which measured oxidase and peroxidase activities. LDL and VLDL values were calculated by the Friedewald formula following the criteria of the III Brazilian Guidelines on Dyslipidemia and Prevention of Atherosclerosis -2011 . Laboratory analyses were carried out according to the Good Clinical Laboratory Practices and the recommendations established by the Brazilian Society of Clinical Pathology/Laboratory Medicine.

\section{Statistical analysis}

The data were described in tables, with frequencies and measures of dispersion of lipids and the establishment of clinical indicators.

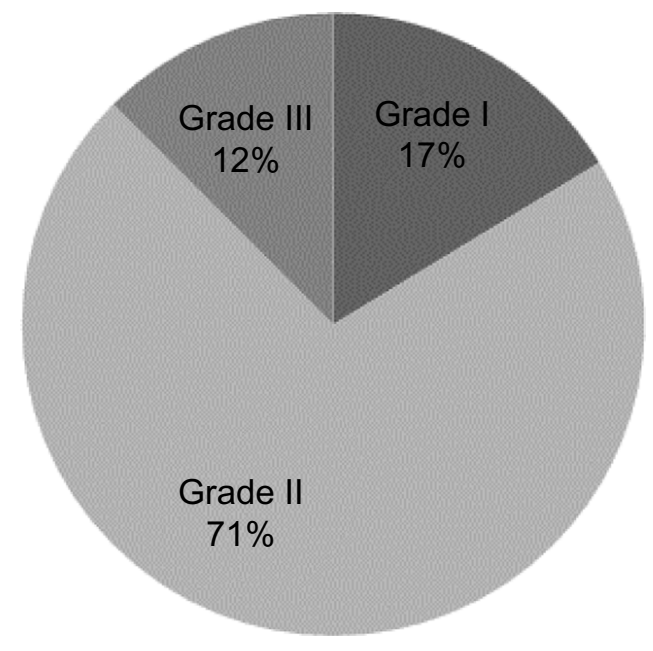

Figure I Clinical distribution of acne lesions among patients.
Table I Lipid profile of adult women with acne compared with grades II and III acne

\begin{tabular}{llll}
\hline Parameters & Acne & $\begin{array}{l}\text { Grade II acne } \\
(\mathbf{n}=\mid \mathbf{5 6})\end{array}$ & $\begin{array}{l}\text { Grade III acne } \\
(\mathbf{n}=\mathbf{2 5})\end{array}$ \\
\hline TC $(\mathrm{mg} / \mathrm{dL})$ & $204.5 \pm 3.9$ & $201.8 \pm 40.8$ & $200.0 \pm 41.9$ \\
$\mathrm{HDL}(\mathrm{mg} / \mathrm{dL})$ & $56.6 \pm 13.7$ & $56.6 \pm 13.3$ & $56.6 \pm 14.5$ \\
$\mathrm{LDL}(\mathrm{mg} / \mathrm{dL})$ & $125.2 \pm 39.9$ & $123.2 \pm 38.6$ & $117.7 \pm 35.4$ \\
VLDL $(\mathrm{mg} / \mathrm{dL})$ & $24.7 \pm 23.7$ & $24.2 \pm 21.1$ & $22.7 \pm 10.5$ \\
$\mathrm{TG}(\mathrm{mg} / \mathrm{dL})$ & $114.6 \pm 61.6$ & $112.9 \pm 60.4$ & $114.6 \pm 52.3$ \\
\hline
\end{tabular}

Note: Data are presented as mean \pm SD.

Abbreviations: TC, total cholesterol; HDL, high-density lipoprotein; LDL, lowdensity lipoprotein; VLDL, very-low-density lipoprotein; TG, triglycerides.

\section{Results}

A total of 416 medical records of patients from the Acnein-Adult-Women Ambulatory Care Clinic (FMABC) were evaluated between the period of January and December of 2012. The epidemiological study sample was of 219 patients, ages ranging from 21 to 61 years (mean of 32.23 years). From this total, 197 records (47.36\%) were excluded given the fact those patients met one or more exclusion criteria.

The predominant clinical grade was papule-pustule acne (grade II) with 156 patients (71\%), followed by grades I and III, with $38(17 \%)$ and $25(12 \%)$ patients, respectively. Patients with comedogenic acne were excluded from laboratory analyses (Figure 1). There was no significant difference between the grade of acne and patients' lipid profile as seen in Table 1, where means and standard deviations of cholesterol and TG levels are compared with grades II and III acne.

TC had a mean of $204.5 \mathrm{mg} / \mathrm{dL}$ (Table 1), with altered levels in 112 patients (51.14\%): 33.79\% borderline high and $17.35 \%$ high. The other 107 patients (48.65\%) found themselves within the desirable range (Table 2). HDL mean was of $56.6 \mathrm{mg} / \mathrm{dL}$ (Table 1), with low levels in $11.42 \%$ of the patients and normal levels in 194 patients (88.58\%) (Table 3). LDL levels in 132 patients (60.27\%) were normal: $29.68 \%$ were within the optimal range and $30.59 \%$ were within near optimal. Altered levels of LDL reached 39.72\%: 52 patients (23.74\%) were within borderline high range, 19 (8.68\%) were within high range and $16(7.30 \%)$ were within very high (Table 4) with a mean of $125.2 \mathrm{mg} / \mathrm{dL}$ (Table 1). VLDL levels

Table 2 Total cholesterol profile of adult women with acne

\begin{tabular}{lll}
\hline Total Cholesterol Classification & $\begin{array}{l}\text { Number of } \\
\text { patients }\end{array}$ & $\begin{array}{l}\% \text { of } \\
\text { patients }\end{array}$ \\
\hline Desirable $(<200 \mathrm{mg} / \mathrm{dL})$ & 107 & $48.9 \%$ \\
Borderline high $(200-239 \mathrm{mg} / \mathrm{dL})$ & 74 & $33.8 \%$ \\
High $(\geq 240 \mathrm{mg} / \mathrm{dL})$ & 38 & $17.3 \%$ \\
Total* & 219 & $100.0 \%$ \\
\hline
\end{tabular}

Note: $*$ Total $=$ total of the sample. 
Table 3 HDL profile of adult women with acne

\begin{tabular}{lll}
\hline $\begin{array}{l}\text { Classification of HDL } \\
\text { cholesterol }\end{array}$ & $\begin{array}{l}\text { Number of } \\
\text { patients }\end{array}$ & $\begin{array}{l}\% \text { of } \\
\text { patients }\end{array}$ \\
\hline Normal $(\geq 40 \mathrm{mg} / \mathrm{dL})$ & 194 & $88.58 \%$ \\
Low $(<40 \mathrm{mg} / \mathrm{dL})$ & 25 & $11.42 \%$ \\
Total* & 219 & $100.00 \%$ \\
\hline
\end{tabular}

Note: $*$ Total $=$ total of the sample.

Abbreviation: HDL, high-density lipoprotein.

were normal in the great majority of the patients $(94.06 \%)$, and only 13 patients $(5.94 \%)$ were within the high range (Table 5) with a mean of $24.7 \mathrm{mg} / \mathrm{dL}$ (Table 1 ).

Finally, TG had a mean of $114.6 \mathrm{mg} / \mathrm{dL}$ (Table 1), with optimal levels in 175 women (79.91\%). Altered levels reached $20.09 \%$ of the patients: 26 were within borderline high range, only $18(8.22 \%)$ were within high range and none of them were within very high range (Table 6).

\section{Discussion}

In the current study, the prevalence of dyslipidemia in the Acne-in-Adult-Women Ambulatory Care Clinic could be observed. Some parameters indicate a possible causal association between acne and dyslipidemia.

The lipid profile of women with grade II and III acne was analyzed, considering the importance of hyperandrogenism in events of adult women with acne. ${ }^{10,28}$ When compared with these mentioned grades, there were no significant alterations in the lipid profile, a fact that complies with the literature. ${ }^{17}$

The major alterations observed were in regards to $\mathrm{TC}$, with $51.14 \%$ of the patients, followed by LDL, with rates as high as $39.72 \%$, and TG, with $20.09 \%$ of the values. HDL and VLDL profiles had fewer abnormal values, with altered rates in $11.42 \%$ and $5.94 \%$ of the cases, respectively. These results, especially of TC and LDL, call the attention to the fact that there seems to be a positive association between dyslipidemia and an acne breakout since an expressive number of the studied patients presented some sort of alteration in their lipid profile. These findings are in consonance with other studies in the literature..$^{25,26}$

Table 4 LDL profile of adult women with acne

\begin{tabular}{lll}
\hline Classification of LDL cholesterol & $\begin{array}{l}\text { Number of } \\
\text { patients }\end{array}$ & $\begin{array}{l}\% \text { of } \\
\text { patients }\end{array}$ \\
\hline Optimal $(<100 \mathrm{mg} / \mathrm{dL})$ & 65 & $29.69 \%$ \\
Near optimal $(100-129 \mathrm{mg} / \mathrm{dL})$ & 67 & $30.59 \%$ \\
Borderline high $(I 30-159 \mathrm{mg} / \mathrm{dL})$ & 52 & $23.74 \%$ \\
High $(160-189 \mathrm{mg} / \mathrm{dL})$ & 19 & $8.68 \%$ \\
Very high $(>189 \mathrm{mg} / \mathrm{dL})$ & 16 & $7.30 \%$ \\
Tota* & 219 & $100.00 \%$ \\
\hline
\end{tabular}

Note: $*$ Total $=$ total of the sample.

Abbreviation: LDL, low-density lipoprotein.
Table 5 VLDL profile of adult women with acne

\begin{tabular}{lll}
\hline $\begin{array}{l}\text { Classification of VLDL } \\
\text { cholesterol }\end{array}$ & $\begin{array}{l}\text { Number of } \\
\text { patients }\end{array}$ & $\begin{array}{l}\% \text { of } \\
\text { patients }\end{array}$ \\
\hline Normal $(\leq 50 \mathrm{mg} / \mathrm{dL})$ & 206 & $94.06 \%$ \\
Increased $(>50 \mathrm{mg} / \mathrm{dL})$ & 13 & $5.94 \%$ \\
Total & 219 & $100.00 \%$ \\
\hline
\end{tabular}

Note: $*$ Total $=$ total of the sample.

Abbreviation: VLDL, very-low-density lipoprotein.

One of these studies was performed with 60 female patients who were divided into two groups, namely, acute acne vulgaris and control group. Patients with acne had higher levels (mean \pm standard deviation) of both TC $(214.83 \pm 5.19 \mathrm{mg} / \mathrm{dL})$ and LDL $(161.3 \pm 3.08 \mathrm{mg} / \mathrm{dL})$ when compared with control group, complying with the final results of this study. ${ }^{25}$ However, low HDL was the most significant alteration $(31.57 \pm 0.83 \mathrm{mg} / \mathrm{dL})$, a fact that was not observed here. ${ }^{25}$

Another study including 166 patients with acne also had divergent results. When compared with control group, no significant alterations in TC levels in patients with acne could be observed. Moreover, there was an expressive decrease in HDL levels and an increase in LDL levels. ${ }^{26}$

Regarding TG, no significant alterations in patients with acne were observed in this study or in the others found in the literature..$^{25,26}$

The current study aimed to relate dyslipidemia to acne and hyperandrogenism regardless of the presence of PCOS. The literature shows that an increase in androgen levels is a characteristic of the PCOS. ${ }^{6,12}$ According to some studies, TC and LDL levels are high whereas HDL levels are low in patients with PCOS. ${ }^{24,29}$

Nevertheless, the purpose of this study was to evaluate patients with acne from the Acne-in-Adult-Women Ambulatory Care Clinic regardless of the presence of PCOS, which may explain the variation in the lipid profile results like the ones observed in the literature.

The increase of androgen levels, insulin secretion, PCOS as well as dyslipidemia are under genetic control according to what has been established in familial studies. ${ }^{13,20,21}$ Still,

Table 6 Triglycerides profile of adult women with acne

\begin{tabular}{lll}
\hline Classification of Triglycerides & $\begin{array}{l}\text { Number of } \\
\text { patients }\end{array}$ & $\begin{array}{l}\% \text { of } \\
\text { patients }\end{array}$ \\
\hline Optimal $(<100 \mathrm{mg} / \mathrm{dL})$ & 175 & $79.91 \%$ \\
Borderline high $(130-159 \mathrm{mg} / \mathrm{dL})$ & 26 & $11.87 \%$ \\
High $(160-189 \mathrm{mg} / \mathrm{dL})$ & 18 & $8.22 \%$ \\
Very high $(>189 \mathrm{mg} / \mathrm{dL})$ & 0 & $0.00 \%$ \\
Total* & 219 & $100.00 \%$ \\
\hline
\end{tabular}

Note: $*$ Total $=$ total of the sample. 
the genetic factor was not evaluated here. In a previous study, it was estimated that families of patients with PCOS are up to 2.7 times more likely to develop metabolic disorders than control-group families and that the relative risk to develop dyslipidemia is 1.8 in family members of patients with PCOS. ${ }^{21}$ Therefore, a further investigation on the genes related to dyslipidemia in this group of patients, comparing the results with the ones found in women of the same age group without acne, would be interesting so that a better analysis on a possible causal association between acne and dyslipidemia would be made possible.

The conclusion was that patients with grades II and III acne are more likely to have TC and LDL elevated regardless of their family history, which may be related to the presence of PCOS. Its correct and early diagnosis can be an important measure for the prevention of the metabolic syndrome in these patients.

\section{Disclosure}

The authors report no conflicts of interest in this work.

\section{References}

1. Koo J. The psychosocial impact of acne: patient's perceptions. $J$ Am Acad Dermatol. 1995;32(5) part 3:S26-S30.

2. Zouboulis CC, Eady A, Philpott M, et al. What is the pathogenesis of acne? Exp Dermatol. 2005;14:143-152.

3. Kurokawa I, et al. New developments in our understanding of acne pathogenesis and treatment. Exp Dermatol. 2009;18(10):821-832.

4. Colonna L, Pacifico V, Lello S, Sorge R, Raskovic D, Primavera G. Skin improvement with two different oestroprogestins in patients affected by acne and polycystic ovary syndrome: clinical and instrumental evaluation. J Eur Acad Dermatol Venereol. 2012;26(11):1364-1371.

5. Strauss JS, Krowchuk DP, Leyden JJ, Lucky AW, Shalita AR, Siegfried EC. Guidelines of care for acne vulgaris management. $J \mathrm{Am}$ Acad Dermatol. 2007;56(4):651-663.

6. Moura HHG, et al. Síndrome do ovário policístico: abordagem dermatológica. [Polycystic ovary syndrome: dermatological approach]. Anais Brasileiros de Dermatologia. 2011; 86(1):111-119. Portuguese.

7. Westerveld HE, Hoogendoom M, de Jong AWF, et al. Cardiometabolic abnormalities in the polycystic ovary syndrome: pharmacotherapeutic insights. Parmacol Ther. 2008;119:223-241.

8. Rachoń D, Teede H. Ovarian function and obesity - interrelationship, impact on women's reproductive lifespan and treatment options. Mol Cell Endocrinol. 2010;316(2):172-179.

9. Azziz R, Snchez A, Knochenhauer ES, et al. Extensive personal experience - androgen excess in women: experience with over 1000 consecutive patients. J Clin Endocrinol Metab. 2004;89(2):453-462.

10. da Cunha MG, Fonseca FL, Machado CD. Androgenic hormone profile of adult women with acne. Dermatology. 2013;226(2):167-171. doi:10.1159/000347196. Epub May 16, 2013.

11. Perkins AC, Maglione J, Hillebrand GG, Myamoto K, Kimball AB Acne vulgaris in women: prevalence across the life span. $J$ Womens Health. 2012;21(2):223-230.
12. Yarak S, Bagatin E, Hassun K, Parada M, Filho ST. Hiperandrogenismo e pele: síndrome do ovário policístico e resistência periférica à insulina. [Hyperandrogenism and skin: polycystic ovary syndrome and insulin resistance]. An Bras Dermatol. 2005;80(4):395-410. Portuguese.

13. Fauser BC, Tarlatzis BC, Rebar RW, et al. Consensus on women's health aspects of polycystic ovary syndrome (PCOS): the Amsterdam ESHRE/ ASRM-Sponsored 3rd PCOS Consensus Workshop Group. Fertil Steril. 2012;97(1):28-38. e25.

14. Rachoń D, Teede H. Ovarian function and obesity - interrelationship, impact on women's reproductive lifespan and treatment options. Mol Cell Endocrinol. 2010;316(2):172-179.

15. El-Mazny A, Abou-Salem N, El-Sherbiny W, El-Mazny A. Insulin resistance, dyslipidemia, and metabolic syndrome in women with polycystic ovary syndrome. Int J Gynaecol Obstet. 2010;109(3):239-241.

16. Repaci A, Gambineri A, Pasquali R. The role of low-grade inflammation in the polycystic ovary syndrome. Mol Cell Endocrinol. 2011;335(1): $30-41$.

17. George R, Clarke S, Thiboutot D. Hormonal therapy for acne. Semin Cutan Med Surg. 2008;27:188-196.

18. Rager KM, Omar HA. Androgen excess disorders in women: the severe insulin-resistant hyperandrogenic syndrome, HAIR-AN. Scientific World Journal. 2006;6:116-121.

19. Diamanti-Kandarakis E, Christakou CD, Kandaraki E, Economou FN. Metformin: an old medication of new fashion: evolving new molecular mechanisms and clinical implications in polycystic ovary syndrome. Eur J Endocrinol. 2010;162(2):193-212.

20. Palomba S, Falbo A, Zullo F, Orio Jr F. Evidence-based and potential benefits of metformin in the polycystic ovary syndrome: a comprehensive review. Endocr Rev. 2009;30(1):1-50.

21. Diamanti-Kandarakis E, Papavassiliou AG, Kandarakis SA, Chrousos GP. Pathophysiology and types of dyslipidemia in PCOS. Trends Endocrinol Metab. 2007;18(7):280-285.

22. Halperin IJL, Kumar SS, Stroup DF, Laredo SE. The association between the combined oral contraceptive pill and insulin resistance, dysglycemia and dyslipidemia in women with polycystic ovary syndrome: a systematic review and meta-analysis of observational studies. Hum Reprod. 2011;26(1):191-201.

23. Massicote MH, Langlois F, Baillargeon JP. Current procedures for managing polycystic ovary syndrome. Expert Rev Obstet Gynecol. 2010;5(1):77-91.

24. Westerveld HE, Hoogendoorn M, de Jong AW, Goverde AJ, Fauser BC, Dallinga-Thie GM. Cardiometabolic abnormalities in the polycystic ovary syndrome: pharmacotherapeutic insights. Pharmacol Ther. 2008;119(3):223-241.

25. Arora MK, Seth S, Dayal S. The relationship of lipid profile and menstrual cycle with acne vulgaris. Clin Biochem. 2010;43(18):1415-1420. Epub September 27, 2010.

26. El-Akawi Z, Abdel-Latif N, Abdul-Razzak K, Al-Aboosi M. The relationship between blood lipids prolife and acne. J Health Sci. 2007;53(5): 596-599.

27. Kaminer MS. The many faces of acne. JAmAcad Dermatol. 1995;32(3): S6-S14.

28. Shaw JC. Acne: effect of hormones on pathogenesis and management. Am J Clin Dermatol. 2002;3(8):571-578.

29. Diamanti-Kandarakis E, Papavassiliou AG, Kandarakis SA, Chrousos, GP. Pathophysiology and types of dyslipidemia in PCOS. Trends Endocrinol Metab. 2007;18:280-285. 


\section{Publish your work in this journal}

Clinical, Cosmetic and Investigational Dermatology is an international, peer-reviewed, open access, online journal that focuses on the latest clinical and experimental research in all aspects of skin disease and cosmetic interventions. All areas of dermatology will be covered; contributions will be welcomed from all clinicians and

basic science researchers globally. This journal is indexed on CAS.

The manuscript management system is completely online and includes a very quick and fair peer-review system, which is all easy to use. Visit http://www.dovepress.com/testimonials.php to read real quotes from published authors.

Submit your manuscript here: http://www.dovepress.com/clinical-cosmetic-and-investigational-dermatology-journal 